\title{
BMJ Open Association of the consumption of common food groups and beverages with mortality from cancer, ischaemic heart disease and diabetes mellitus in Serbia, 1991-2010: an ecological study
}

\author{
Milena Ilic, ${ }^{1}$ Irena llic, ${ }^{2}$ Goran Stojanovic, ${ }^{3}$ Ivana Zivanovic-Macuzic ${ }^{4}$
}

To cite: Ilic M, llic I, Stojanovic G, et al. Association of the consumption of common food groups and beverages with mortality from cancer, ischaemic heart disease and diabetes mellitus in Serbia, 1991-2010: an ecological study. BMJ Open 2016;6: e008742. doi:10.1136/ bmjopen-2015-008742

- Prepublication history for this paper is available online. To view these files please visit the journal online (http://dx.doi.org/10.1136/ bmjopen-2015-008742).

Received 15 May 2015 Revised 24 November 2015 Accepted 7 December 2015

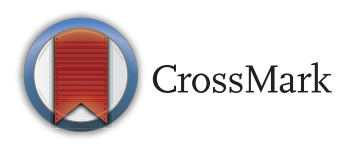

For numbered affiliations see end of article.

Correspondence to Professor Milena Ilic; drmilenailic@yahoo.com

\section{ABSTRACT}

Objectives: This paper reports association between mortality rates from cancer, ischaemic heart disease and diabetes mellitus and the consumption of common food groups and beverages in Serbia.

Design: In this ecological study, data on both mortality and the average annual consumption of common food groups and beverages per household's member were obtained from official data-collection sources. The multivariate linear regression analysis was used to determine the strength of the associations between consumption of common food groups and beverages and mortality rates.

Results: Markedly increasing trends of cancer, ischaemic heart disease and diabetes mellitus mortality rates were observed in Serbia in the period 1991-2010. Mortality rates from cancer were negatively associated with consumption of vegetable oil $(p=0.005)$ and grains $(p=0.001)$, and same was found for ischaemic heart disease $(p=0.002$ and 0.021 , respectively), while consumption of other dairy products showed a significant positive association ( $p<0.001$ and $p=0.032$, respectively). In men and women, mortality rates from diabetes mellitus showed a significant positive association with consumption of poultry ( $p=0.014$ and 0.004 , respectively). Consumption of beef and grains showed a significant negative association with cancer mortality rates in both genders $(p=0.002$ and $p<0.001$ in men, and $p<0.001$ and $p=0.014$ in women, respectively), while consumption of cheese was negatively associated only in men $(p<0.001)$. Mortality from diabetes mellitus showed a significant positive association with consumption of animal fat and other dairy products only in women $(\mathrm{p}=0.003$ and 0.046 , respectively).

Conclusions: Association between unfavourable mortality trends from cancer, ischaemic heart disease and diabetes mellitus, and common food groups and beverages consumption was observed and should be assessed in future analytical epidemiological studies. Promotion of healthy diet is sorely needed in Serbia.

\section{Strengths and limitations of this study}

- To the best of our knowledge, this populationbased ecological study is the first to document a relationship between mortality from cancer, ischaemic heart disease and diabetes mellitus, and consumption of food and beverages in Serbia.

- Mortality rates from cancer, ischaemic heart disease and diabetes mellitus in Serbia have increased during the past two decades, and Serbia tops the list of European countries with highest mortality rates.

- We found that the consumption of beef and grains was negatively associated with mortality rates from cancer in both genders, while consumption of other dairy products showed a significant positive association. Consumption of vegetable oil showed a significant negative association with mortality rates from ischaemic heart disease in both genders, while consumption of beer was positively associated. Association between consumption of poultry and mortality rates from diabetes mellitus was significantly positive both in men and women.

- The inability to fully control confounding factors in assessing relationships between mortality and consumption of food and beverages in Serbia is the limitation of this study.

- Findings have important implications for the promotion of a healthy diet in Serbia.

\section{BACKGROUND}

Cancer, ischaemic heart disease and diabetes mellitus are the most common causes of death in developed countries. ${ }^{1-3}$ The top two diseases, ischaemic heart disease and cancer, accounted for $47.5 \%$ of all deaths in the USA in $2010 .^{2}{ }^{3}$ Cardiovascular diseases are the main cause of death in the European Union: these account for $42 \%$ of all deaths in the total population. ${ }^{1}$ Diabetes was the 
underlying cause in $2.8 \%$ of all deaths in the USA in 2010. ${ }^{3}$ Worldwide, diabetes caused 1.4 million deaths (2.6\% of all causes) in 2011, an increase from 1.0 million $(1.9 \%)$ deaths in $2000 .^{4}$

In the past two decades, cardiovascular mortality declined steeply in the European Union and USA due to decrease in the ischaemic heart disease and stroke mortality. ${ }^{2}$ Since 1990 s, decreased mortality trend from all types of cancer was reported in the USA. ${ }^{2}$ In contrast, death rates from diabetes mellitus in the same time interval increased, yielding a net annual increase of $1.9 \%$. Many predictions indicate a growing burden of diabetes, particularly in developing countries. ${ }^{6}$ In some European countries, most migrant groups (particularly migrants from North Africa, South Asia or countries with low gross domestic product) have higher diabetes mortality rates than the local-born populations. ${ }^{7}$ Mortality varying by place and population has always been used to generate hypotheses on causation. Many epidemiological studies have identified correlation between mortality trends from cancer, coronary heart disease and diabetes mellitus, and food consumption. ${ }^{8-10}$

Low rates of cancer and ischaemic heart disease in southern European countries (Greece and Italy, in particular) are traditionally explained by the 'Mediterranean diet'. '11 'Mediterranean diet' means high consumption of olive oil, legumes, unrefined cereals, fruit and vegetables, moderate consumption of dairy products (mostly cheese and yogurt), fish and wine and low consumption of meat. Moderate consumption of alcohol together with other subtly beneficial lifestyles was associated with $22 \%$ lower risk of death. ${ }^{12}$ In Latin America, the per capita supply of milk showed a strong positive correlation with incidence of childhood type 1 diabetes mellitus. ${ }^{13}$ Inverse associations were observed for eggs and coffee consumption in several studies, while other studies did not confirm such findings. ${ }^{14-16}$

Serbia (officially the Republic of Serbia) is a small country in southeast Europe: according to World Bank estimates, Serbia today is an upper middle income country with a dominant service sector, followed by industry and agriculture. ${ }^{17}$ However, Serbia has experienced dramatic changes over the past decades in addition to civil wars and the dissolution of the former Yugoslavia in the 1990s: the United Nations sanctions and trade embargo in 1992, the political isolation and the collapse of the economy in 1993, NATO bombing in 1999 and democratic socioeconomic changes in the 2000s, Kosovo's unilateral declaration of independence in 2008, and transition to market economy and financial crisis that marked the beginning of the century. Since the 1990s, Serbia has the largest refugee population in Europe-about half a million refugees and internally displaced persons sought refuge in the country following the series of Yugoslavian wars. As per the 2002 census, Serbs are the largest ethnic group in Serbia (representing $83 \%$ of the total population); another 37 ethnicities also live on its territory (including Hungarians who are the largest ethnic minority in Serbia and represent $3.9 \%$ of the country's population, followed by Bosniaks and Roma with a similar share of around $2 \%$, etc). Serbian cuisine is largely heterogeneous and includes characteristics of the Balkans, the Mediterranean, Turkish and Hungarian cuisines. Slivovitz, a highly alcoholic drink, is a famous rakia which is considered the national drink of Serbia.

The prominent immediate effect of wars and disintegration of Serbia significantly increased mortality from cancer and ischaemic heart disease during the past two decades. ${ }^{18-20}$ Serbia tops the list of European countries with highest cancer mortality rates. ${ }^{18} 19$ Since 1990 s, cardiovascular disease and cancer became the first and second most prevalent causes of death in Serbia. ${ }^{21}{ }^{22} \mathrm{In}$ the same period, diabetes mellitus represented the cause for $3 \%$ of all deaths. These three causes of death together accounted for almost $80 \%$ of the total mortality in Serbia, with increasing tendency. There is scant information regarding the impact of diet on mortality in Serbia. This paper aimed to assess the time trend in mortality from most common diseases in Serbia, and to analyse the relationship between consumption of common food groups and beverages and mortality rates.

\section{MATERIAL AND METHODS \\ Data source}

In this ecological study data on both health outcome (mortality from cancer, ischaemic heart disease and diabetes mellitus) and the exposure (the average annual consumption of common food groups and beverages per household's member) were obtained from official data-collection sources-the National Statistical Office of the Republic of Serbia. ${ }^{21}$

Data on persons who died of cancer (site codes 140-208 revision 9 and codes C00-C97 revision 10 of the International Classification of Diseases-ICD), ischaemic heart diseases (ICD-9 codes 410-414 and ICD-10 codes I20-I25), and diabetes mellitus (ICD-9 code 250 and ICD-10 codes E10-E14) were obtained from the National Statistical Office of the Republic of Serbia (unpublished data). Causes of death in Serbia are available from 1997 according to the ICD-10, and from the previous period according to ICD-9.

Data on causes of death are collected through the Death Certificate Form (DEM-2) (Official Gazette SR Serbia No. 8/2005). In Serbia, determination of death and cause of death are the responsibility of the physician. Death data are collected and submitted by registrars. Data on the deceased and on the cause of death are collected routinely for the entire territory of Serbia. All public hospitals are obliged by law to send individual hospitalisation reports to regional institutes of public health which aggregate the data and send a report to the Institute of Public Health of Serbia. Mortality statistics include all (100\%) death occurrences in Serbia. The WHO assessed the quality of the official mortality 
statistics in Serbia as medium-quality (criterion used: completeness reporting is $>90 \%$, and ill-defined causes and injury deaths with undetermined intent appear on $<10 \%$ of registrations). ${ }^{23}$

The study comprised the entire population of the Republic of Serbia during the period 1991-2010. Data for 1998-2010 are not available for the Autonomous Province of Kosovo and Metohia, which declared itself independent in 2008. Data on the number and composition of the Serbian population by gender and age were presented according to 1991 and 2002 censuses, while for intercensus years the estimates of the resident population were obtained from the national Statistical Office database. The analysis was conducted on the entire Serbian population (approximately 7.5 million inhabitants). ${ }^{21}$ Since 1990 s, Serbia had the largest internally displaced persons and refugee population in Europe (constituting $7 \%$ to $7.5 \%$ of its population) for whom data were included in the Serbian population and could not be set aside as a special group.

The study was conducted between June 2013 and September 2014. Cancer, ischaemic heart disease and diabetes mellitus mortality was estimated for the period 1991-2010.

The National Statistical Office of the Republic of Serbia has conducted a survey of household and individual food and beverages consumption in Serbia-the Household Budget Survey. ${ }^{24}$ The Household Budget Survey in Serbia is conducted annually since the 1960s, and is harmonised with international standards and recommendations (Eurostat, International Labour Organisation and the United Nations) from 2003, which provides grounds for an international comparison of data. The Household Budget Survey covered the whole territory of the Republic of Serbia. The household, either multimember (a community of persons whose members live together in the same dwelling unit and spend realised income jointly) or one member (single person, living alone and spending one's own income), chosen according to the sample plan was the survey unit. Each year, the survey comprises a nationally representative sample of non-institutionalised persons residing in Serbia. The sample is a two-stage, stratified sample. The first stage units are enumeration districts, and the second stage units are households. Sample selection was carried out by selecting the first stage units (enumeration districts) in proportion to the number of households, and the second stage units (households) were selected with equal probability (simple random selection). According to the EUROSTAT recommendations, total number of households predicted for surveying is 4800 for the Republic of Serbia. Also, as recommended by EUROSTAT, out of the total number of households envisaged for the survey, the lowest percentage of households that must be surveyed is $85 \%$ (which was achieved for each year). Given that a household in Serbia consists on an average of three members, the household budget survey includes about 13500-14500 inhabitants.
Data were collected for the whole observed year (from 1 January to 31 December). Every 15 days, 200 households have been chosen to keep a diary on personal consumption of food and beverages (thereby taking into account effects that seasonal variations have on the diet). Diary method has been applied in this survey: each surveyed household keeps a diary (statistical form D-1) for the reference period. The survey collects data on household consumption, that is, data on basic elements of individual consumption. The substitution of households is not predicted. Diary of the consumed quantities of food and beverages in every household was kept by a chosen person (it was the person responsible for food in the house, most often a housewife). Specially trained surveyors visit the households at least three times for the purpose of helping with filling in the diary.

\section{Measures}

Three types of death rates were calculated: crude, specific (age-specific, sex-specific) and age-standardised. Foremost, number of deaths from cancer, ischaemic heart disease and diabetes mellitus were included in the numerator for mortality rates, while Serbian population data was used as the denominator for each year. Then, the standardisation was performed by direct method (Segi's World standard population was used as standard population, stratified by 5 -year age strata). ${ }^{25}$ Age-standardised mortality rates are expressed as deaths per 100000 persons. Linear trend model was used to examine trend of mortality rates from cancer, ischaemic heart disease and diabetes mellitus.

There are about 80 food items listed in the Household Budget Survey. For ease of presentation of the consumption, list of consumed quantities of food and beverages is aggregated into several groups: meat (beef-fresh and frozen, pork-fresh and frozen, poultry-fresh and frozen, fish-fresh and frozen and canned, other kind of meat-fresh and frozen mutton and goat meat and dried and processed meat-including dried bacon, salami and sausages, hot dogs and debreziner, and other sausage products, canned and manufactured meat), eggs, dairy (milk, cheese and other dairy products (including yoghurts, butter, cream and sour cream), fats (animal fat: including pork fat, suet, lard, raw bacon) and oils (sunflower oil, and other vegetable oils), fruits (citrus fruits, bananas, apples, grapes, other kind of fruits and manufactured fruits), vegetables (potatoes, cabbage, tomatoes, peppers, bean, carrots, parsley, celery and similar vegetables, onion, garlic and leek, other kind of vegetables and manufactured vegetables), coffee, alcohol beverages (beer, wine, hard drinks), sweets and sweeteners (biscuits, chocolate, honey, sugar) and grains (bread and cereals, flour and products from flour, pastas and other similar products, rice). Food groups and beverages were represented by following units: meats (kg), eggs (piece), milk (L), cheese $(\mathrm{kg})$, other dairy products $(\mathrm{L})$, animal fat $(\mathrm{kg})$, vegetable oil $(\mathrm{L})$, fruits $(\mathrm{kg})$, vegetables $(\mathrm{kg})$, coffee 
$(\mathrm{kg})$ and beverages (L). Data quality assessment by phone was performed on a random sample ( $10 \%$ of surveyed households).

\section{Statistical analysis}

We examined the relationship between mortality rates and consumption of the common food groups and beverages by calculating a number of bivariate correlation coefficients-the Pearson's correlation coefficients (r). In addition, the explanatory variables might be correlated among themselves (possible confounders). The aim of multivariate linear regression analysis was to assess the strength of the relationship between independent variables (consumption of common food groups and beverages) on variation in the dependent variable (mortality rates). Here we used the Stepwise (backward deletion) multivariate linear regression method. In trying to disentangle the relationships involved in a set of independent variables, we checked collinearity diagnostics which resulted in omitting variables that showed significant mutual correlation $(r>0.9)$. In order to control the influence of gender on the association between consumption of food and beverages and mortality rates from cancer, ischaemic heart disease and diabetes mellitus, we conducted the multivariate linear regression analysis for men and women separately. Multivariate linear regression analysis was used to determine the $\beta$ coefficient (with 95\% CIs). $\beta$-unstandardised coefficient indicates how much the dependent variable varies with one independent variable when all other independent variables are held constant. Two-sided $\mathrm{p}$ values were reported and considered to indicate statistical significance when lesser than 0.05. All statistical analyses were conducted using the Statistical Package for Social Sciences software (SPSS Inc, V.20.0, Chicago, Illinois, USA).

\section{RESULTS}

In Serbia (without the Autonomous Province of Kosovo and Metohia), the markedly increasing trends in mortality rates from cancer $(y=119.8 x+1.2, p<0.001)$, ischaemic heart disease $(\mathrm{y}=68.8 \mathrm{x}+0.6, \mathrm{p}=0.025)$ and diabetes mellitus $(\mathrm{y}=14.1 \mathrm{x}+0.1, \mathrm{p}=0.001)$ were observed during the 1991-2010 period (figure 1). The significant increase in mortality rates was found in both sexes, with the exception of insignificant increase in mortality rates from ischaemic heart disease in men only (data not shown).

Pearson's correlation coefficients between agestandardised mortality rates and per capita food and beverages consumption are shown in table 1 . The mortality rates for all three selected chronic diseases in Serbia were positively correlated with consumption of eggs $(\mathrm{r}=+0.890,+0.544$ and +0.680 , respectively $)$, and negatively correlated with animal fat $(\mathrm{r}=-0.892,-0.473$ and -0.501 , respectively) and hard drinks consumption $(\mathrm{r}=-0.974,-0.519$ and -0.691 , respectively). In contrast, per capita consumption of pork and cheese was not correlated with any of the observed mortality rates.

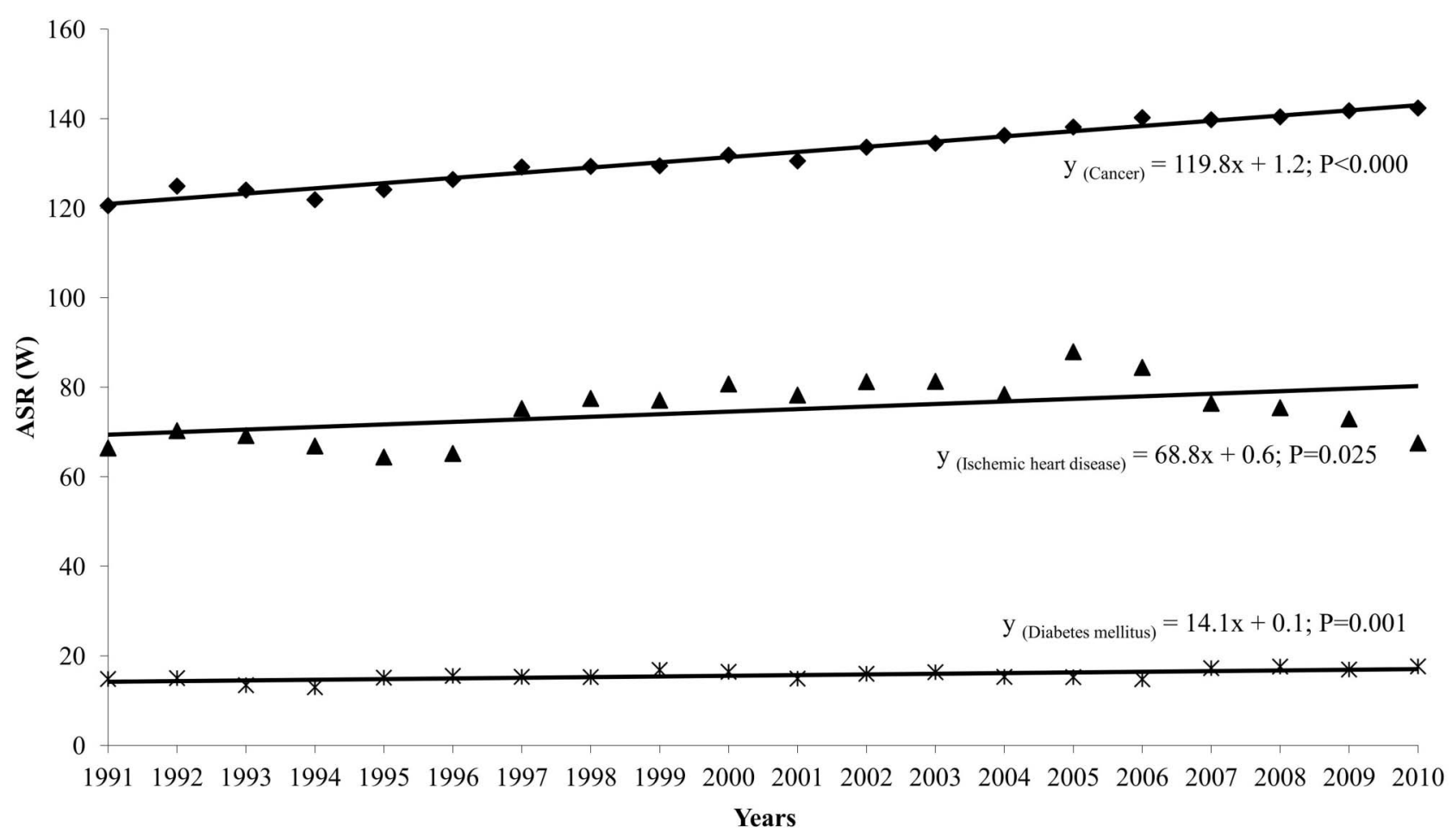

ASR $(W)=$ Age Standardized Rate of mortality (per 100000 persons, using direct method, by Segi's World Standard Population)

Figure 1 Trends in cancer, ischaemic heart disease and diabetes mellitus mortality rates in Serbia, excluding the Autonomous Province of Kosovo and Metohia, 1991-2010. 
Table 1 Pearson's correlation coefficients $(r)$ for per capita food and beverages consumption with mortality from cancer, ischaemic heart disease and diabetes mellitus (age-standardised mortality rates per 100000 persons, using direct method, by Segi's World Standard Population) in Serbia, 1991-2010

\begin{tabular}{|c|c|c|c|}
\hline Food groups and beverages (unit) & Cancer mortality & $\begin{array}{l}\text { Ischaemic heart } \\
\text { disease mortality }\end{array}$ & $\begin{array}{l}\text { Diabetes mellitus } \\
\text { mortality }\end{array}$ \\
\hline \multicolumn{4}{|l|}{ Meats } \\
\hline Beef $(\mathrm{kg})$ & $-0.740^{\star \star}$ & $-0.565^{\star \star}$ & -0.363 \\
\hline Pork (kg) & +0.147 & -0.346 & +0.164 \\
\hline Poultry (kg) & $+0.895^{\star \star}$ & +0.314 & $+0.748^{\star \star}$ \\
\hline Fish (all kinds) (kg) & $+0.861^{\star \star}$ & 0.349 & $+0.612^{\star \star}$ \\
\hline Other meat $(\mathrm{kg})$ & $-0.577^{\star}$ & $-0.541^{*}$ & -0.265 \\
\hline Dried meat (kg) & $+0.878^{\star \star}$ & +0.235 & $+0.692^{\star \star}$ \\
\hline Eggs (piece) & $+0.890^{\star \star}$ & $+0.544^{\star}$ & $+0.680^{\star *}$ \\
\hline \multicolumn{4}{|l|}{ Dairy } \\
\hline Milk (L) & $-0.695^{\star \star}$ & -0.168 & -0.301 \\
\hline Cheese (kg) & +0.100 & -0.298 & +0.131 \\
\hline Other dairy products $(\mathrm{L})$ & $+0.880^{\star \star}$ & +0.357 & $+0.625^{\star \star}$ \\
\hline \multicolumn{4}{|l|}{ Fats and oils } \\
\hline Animal fat $(\mathrm{kg})$ & $-0.892^{* \star}$ & $-0.473^{\star}$ & $-0.501^{\star}$ \\
\hline Vegetable oil (L) & $+0.674^{\star \star}$ & -0.092 & $+0.606^{\star \star}$ \\
\hline Fruits (all kinds) (kg) & $+0.760^{\star \star}$ & +0.300 & $+0.737^{\star \star}$ \\
\hline Vegetables (all kinds) (kg) & $+0.749^{\star \star}$ & +0.265 & $+0.723^{\star *}$ \\
\hline Coffee (kg) & $+0.558^{\star}$ & +0.015 & $+0.516^{\star}$ \\
\hline \multicolumn{4}{|l|}{ Alcohol beverages } \\
\hline Beer (L) & +0.492 & +0.379 & $+0.600^{*}$ \\
\hline Wine (L) & $-0.571^{*}$ & $-0.655^{\star \star}$ & -0.349 \\
\hline Hard drinks (L) & $-0.974^{\star \star}$ & $-0.519^{\star}$ & $-0.691^{\star \star}$ \\
\hline Sweets and sweeteners (kg) & $+0.536^{\star}$ & -0.151 & $+0.464^{\star}$ \\
\hline Grains (kg) & $-0.843^{* *}$ & -0.346 & -0.397 \\
\hline
\end{tabular}

A multivariate linear regression analysis revealed positive association between cancer mortality rates and consumption of poultry $(\beta=+1.13$, 95\% CI 0.62 to 1.65 , $\mathrm{p}<0.001)$, milk $(\beta=+0.10,95 \%$ CI 0.02 to $0.17, \mathrm{p}=0.016)$ and other dairy products $(\beta=+0.45,95 \%$ CI 0.30 to 0.60 , $\mathrm{p}<0.001)$ and negative association with consumption of beef $(\beta=-1.42,95 \%$ CI -1.93 to $-0.92, \mathrm{p}<0.001)$, vegetable oil $(\beta=-1.34,95 \%$ CI -2.21 to $-0.48, p=0.005)$ and grains $(\mathrm{B}=-0.13,95 \% \mathrm{CI}-0.21$ to $-0.06, \mathrm{p}=0.002$; table 2). Also, the multivariate linear regression analysis showed positive association between ischaemic heart disease mortality rates and consumption of beer $(\beta=+1.36,95 \%$ CI 0.72 to $2.00, \mathrm{p}<0.001)$ and other dairy products $(\beta=+0.49,95 \%$ CI 0.05 to $0.92, p=0.032)$, and negative association with consumption of vegetable oil $(\beta=-4.82,95 \%$ CI -7.20 to $-2.45, p=0.001)$, cheese $(\beta=-2.50,95 \%$ CI -4.41 to $-0.59, p=0.014)$ and grains $(\beta=-0.25,95 \%$ CI -0.47 to $-0.04, p=0.021)$. Between the consumption of poultry and mortality rates from diabetes mellitus a positive association was observed $(\beta=+0.61,95 \%$ CI 0.33 to $0.90, p<0.001)$.

The animal fat, eggs and other dairy products consumption was significantly positively related with cancer mortality rates in men $(p<0.001$; table 3$)$. Beef and grains consumption showed a significant negative association with cancer mortality rates in both genders $(\mathrm{p}=0.002$ and $\mathrm{p}<0.001$ in men, respectively; $\mathrm{p}<0.001$ and $\mathrm{p}=0.014$ in women, respectively), while consumption of cheese was negatively associated with mortality rate in men only $(p<0.001)$. For both genders, the consumption of vegetable oils was negatively $(p<0.001$ in men, and $p=0.001$ in women) and beer consumption was positively ( $p=0.018$ in men, and $p<0.001$ in women) associated with mortality rates from ischaemic heart disease. Association between poultry consumption and mortality rates from diabetes mellitus was significantly positive in men and women ( $p=0.014$ and 0.004 , respectively). Consumption of animal fat and other dairy products showed significant positive association with mortality from diabetes mellitus only in women.

\section{DISCUSSION}

One of the main findings in this study was the significant increase of mortality from cancer, ischaemic heart disease and diabetes mellitus within the observed period in Serbia. According to the WHO estimates, in recent years Serbia has been the country with the highest mortality due to cancer and diabetes mellitus in Europe, while mortality from ischaemic heart disease was lower in comparison to the rest of the European Region countries. ${ }^{1}{ }^{22}$ Although mortality from coronary heart diseases has continued to decline in the European Union (27 countries), the USA, Australia, Japan and most Latin 
Table 2 Association of the consumption of food and beverages with mortality from cancer, ischaemic heart disease and diabetes mellitus in Serbia, 1991-2010; multivariate linear regression analysis

\begin{tabular}{|c|c|c|c|c|c|c|c|c|}
\hline \multirow[b]{3}{*}{ Mortality } & \multicolumn{8}{|c|}{ Food and beverages (items) } \\
\hline & \multicolumn{4}{|l|}{ Positive } & \multicolumn{4}{|l|}{ Negative } \\
\hline & Items & $\boldsymbol{\beta}$ & $95 \% \mathrm{Cl}$ & p Value & Items & $\boldsymbol{\beta}$ & $95 \% \mathrm{Cl}$ & p Value \\
\hline \multicolumn{9}{|l|}{ Cancer } \\
\hline & Poultry & +1.13 & (0.62 to 1.65$)$ & $<0.001$ & Beef & -1.42 & $(-1.93$ to -0.92$)$ & $<0.001$ \\
\hline & Milk & +0.10 & $(0.02$ to 0.17$)$ & 0.016 & Vegetable oil & -1.34 & $(-2.21$ to -0.48$)$ & 0.005 \\
\hline & Other dairy products & +0.45 & (0.30 to 0.60$)$ & $<0.001$ & Grains & -0.13 & $(-0.21$ to -0.06$)$ & 0.002 \\
\hline \multicolumn{9}{|c|}{ Ischaemic heart disease } \\
\hline & Beer & +1.36 & (0.72 to 2.00$)$ & $<0.001$ & Vegetable oil & -4.82 & $(-7.20$ to -2.45$)$ & 0.001 \\
\hline & Other dairy products & +0.49 & (0.05 to 0.92$)$ & 0.032 & Cheese & -2.50 & $(-4.41$ to -0.59$)$ & 0.014 \\
\hline & & & & & Grains & -0.25 & $(-0.47$ to -0.04$)$ & 0.021 \\
\hline \multicolumn{9}{|c|}{ Diabetes mellitus } \\
\hline & Poultry & +0.61 & (0.33 to 0.90$)$ & $<0.001$ & & & & \\
\hline
\end{tabular}

American countries, unfavourable trends are still observed in the Russian Federation and other countries of the former Soviet Union (Ukraine, Belarus, etc). ${ }^{26}$ In Western Europe, cancer mortality has steadily declined since the late 1980s, but in central/eastern Europe, mortality from major cancer sites has been increasing up to the late 1990s/early 2000s. ${ }^{27}$ Diabetes mellitus accounted for $6 \%$ of deceased adults in the African Region, and $15.7 \%$ in the North American Region, where diabetes is a major cause of premature mortality. ${ }^{28}$ Diabetes mellitus prevalence and mortality is increasing, particularly in low income and middle income countries. $^{622}$ These unfavourable trends are coincident with dramatic socioeconomic changes that occurred in developing countries, especially in the former communist countries. Thus, these countries have undergone 'westernisation', including the adoption of the new dietary habits (such as increased animal fat and red meat consumption, increased consumption of processed food and low vegetable intake), obesity and physical inactivity, cigarette smoking and alcohol use which characterise newly economically developed countries. ${ }^{29}$ Between the two time periods over 43 years $(1961 / 1965-2000 / 2004)$, Serbia, like other countries in the Mediterranean area who were a part of the seven countries study, has also undergone this phase of 'westernisation' of food habits and experienced a convergence in terms of non-Mediterranean food groups. ${ }^{30}$ The devastating economic crisis-exacerbated by the sanctions and the wars in former Yugoslavia, hundreds of thousands of refugees, unemployment, the collapse of the national currency and the inability to purchase needed medications, the deterioration of public health and then by the bombing of Serbia, further affected the general circumstances in Serbia. ${ }^{31}$ Diet plays an important role in the occurrence of these diseases, as indicated in a number of epidemiological studies. ${ }^{23} 32-34$

The association between consumption of food and beverages and mortality rates from cancer, ischaemic heart disease and diabetes mellitus has been found to

Table 3 Association of the consumption of food and beverages with mortality from cancer, ischaemic heart disease and diabetes mellitus in Serbia, by gender, 1991-2010; multivariate linear regression analysis

\begin{tabular}{|c|c|c|c|c|c|c|c|c|}
\hline \multirow[b]{3}{*}{ Mortality } & \multicolumn{8}{|c|}{ Food and beverages (items) } \\
\hline & \multicolumn{4}{|l|}{ Men } & \multicolumn{4}{|l|}{ Women } \\
\hline & Positive & p Value & Negative & p Value & Positive & p Value & Negative & p Value \\
\hline \multicolumn{9}{|l|}{ Cancer } \\
\hline & Animal fat & $<0.001$ & Beef & 0.002 & Poultry & 0.048 & Beef & $<0.001$ \\
\hline & Eggs & $<0.001$ & Cheese & $<0.001$ & Milk & 0.003 & Grains & 0.014 \\
\hline & $\begin{array}{l}\text { Other dairy } \\
\text { products }\end{array}$ & $<0.001$ & Grains & $<0.001$ & Other dairy products & $<0.001$ & & \\
\hline \multicolumn{9}{|c|}{ Ischaemic heart disease } \\
\hline & Beer & 0.018 & Vegetable oil & $<0.001$ & Beer & $<0.001$ & $\begin{array}{l}\text { Vegetable oil } \\
\text { Cheese }\end{array}$ & $\begin{array}{l}0.001 \\
0.003\end{array}$ \\
\hline \multicolumn{9}{|c|}{ Diabetes mellitus } \\
\hline & Poultry & 0.014 & & & Animal fat & 0.003 & & \\
\hline & & & & & Poultry & 0.004 & & \\
\hline & & & & & Other dairy products & 0.046 & & \\
\hline
\end{tabular}


vary in significance and magnitude across countries. $^{6} 111535$

Numerous ecological studies showed association between cancer mortality rates and consumption of some animal products (meat, milk, fish and eggs), sweeteners, some fats, grains and vegetables. ${ }^{36}$ The most consistent association was between cancer mortality and animal fat consumption, ${ }^{38} 39$ but was not confirmed in some other studies. ${ }^{15} 40$ In our study, consumption of animal fat and eggs was associated with cancer mortality in men only. This probable effect has been related to specific micronutrients (cholesterol, fatty acids, etc) contained in egg yolk and fats. ${ }^{41}$ Secular mortality trend from colorectal cancer in Spain has been positively correlated with consumption of poultry, vegetables and fruit. $^{35}$ Northern Europe seems to have adopted a healthier dietary pattern during recent decades, possibly due to both the improvements in availability of food groups (such as olive oil, fruits, vegetables, fish and seafood) and the implementation of nutrition education. $^{30}$ We found that the consumption of beef and grains was negatively associated with mortality from cancer in both genders, while consumption of other dairy products showed a significant positive association. These results could be explained with the intake of nutrients which contain grains, beef and dairy products (such as high-quality proteins, fibres, vitamins and minerals) which may have anticarcinogenic properties. ${ }^{42}$ Besides, substantial differences according to gender may be the result of different exposure to lifestyle-related risk factors such as smoking habits, sedentary life-style, obesity and diabetes.

According to the Data Food Networking (DAFNE) project, coronary heart disease mortality was not significantly correlated with per capita consumption of meat, fish, milk and dairy products, eggs and ethanol. ${ }^{40}$ In 18 European countries, coronary mortality was negatively correlated with olive oil consumption. ${ }^{26} 34$ Increased consumption of palm oil and other oil crops is related to higher ischaemic heart disease mortality rates in developing countries. ${ }^{15} 33$ Our study revealed that vegetable oil consumption was negatively associated with mortality rates from ischaemic heart disease in both genders, while consumption of beer was positively associated. Some studies have produced different findings. ${ }^{44}$ Beer consumption has been associated with an increased coronary mortality rate probably due to a decrease in antioxidant capacity and changes in lipid profiles and inflammatory markers (eg, $\mathrm{C}$ reactive protein, interleukin 6 , tumour necrosis factor $\alpha){ }^{45}$ Decreased mortality has been associated with the consumption of vegetable oils, which are rich with monounsaturated and polyunsaturated fatty acids with well-known cardioprotective effects ${ }^{46}$ A positive correlation between mortality from coronary heart disease and eggs consumption was observed in a study involving 40 countries, ${ }^{47}$ in contrast to the results in some other studies. ${ }^{15}$ Our study failed to demonstrate association between eggs consumption and mortality from ischaemic heart disease, which could be explained with the hidden intercorrelations among some components of food and beverages which were aggregated into several groups or with confounding effects of some lifestyle factors (age, smoking, physical inactivity, hypertension and diabetes mellitus).

Consumption of poultry had a positive association with mortality from diabetes mellitus in both genders in Serbia. Although the saturated fat load in poultry may be lower than that in typical red meats, poultry provides no fibres or complex carbohydrates, and this could be the possible explanation for the association. Positive association between consumption of animal fat and other dairy products and mortality from diabetes mellitus was noticed in women in Serbia. The detrimental effects reported for animal fat and dairy products may be due to the effects of saturated fatty acids in these food sources. ${ }^{48}$ Studies inquiring into the role of other dairy products as a heterogeneous food group (including specific low-fat and high-fat dairy foods, butter) in diabetes mellitus mortality have not yielded consistent results. ${ }^{49}$ This positive association may be confounded by genetic, psychosocial, or lifestyle-related factors (eg, cigarette smoking, obesity, physical inactivity, etc).

\section{Strengths and limitations of the study}

This study is the first to document a relationship between increased mortality from cancer, ischaemic heart disease and diabetes mellitus, and consumption of food and beverages in Serbia.

The longitudinal nature of our national-level data enabled us to analyse the link between mortality trends and food and beverages consumption. The Serbian mortality statistics data is considered comprehensive and reliable according to the WHO standards. ${ }^{23}$ Also, the proportion of deaths assigned to ill-defined cause-of-death codes (revision 9 codes 780-799 and revision 10 codes R00-R99) in the observed period in Serbia was on average $6.8 \%$, with a non-significant decreasing trend $(p=0.137) .^{21}$ Consequently, changes in the ICD classification over the time period studied could not have a substantial effect on changes in the mortality rates from cancer, ischaemic heart disease and diabetes mellitus in Serbia. Also, the Household Budget Survey in Serbia was harmonised with the international standards and recommendations. ${ }^{21}$ Assessment of the quality of data on consumption of foods and beverages was performed quarterly in each of the households by phone on a random sample ( $10 \%$ of surveyed households). Finally, our study may be useful in the generation of new hypotheses concerning the dietary aetiology of these most common chronic diseases in Serbia, which should be evaluated by further analytical epidemiological researches.

Admittedly, this ecological study has some limitations. First, this ecological study has examined relationship between outcome and exposure at the population level, 
whereas this association may not exist at the individual level. Thus, the use of average exposure levels may mask more complicated relationships with the disease. Also, very important problems in this study refer to the temporal ambiguity, collinearity and confounding. Multivariate analysis has helped in the control of confounding and multicollinearity in our study, but we cannot adjust well for most of relevant exposures (including consumption of cigarettes, obesity, physical activity, occupation, level of education, reproductive characteristics, etc) for which data were not available for the entire Serbian population for the study period. Lack of incidence data for these chronic diseases in Serbia in the observed period may be a source of selection bias in our study because we did not have data on how long the people had the disease. ${ }^{21}$ For example, this ecological study cannot answer whether the men who died from cancer in Serbia were those who actually had a high animal fat diet in the study period. In this study, some measurement errors were inevitable because food consumption was self-reported and maybe incorporated subtle errors due to misunderstandings, misreporting or non-response from the randomly selected households. Also, this ecological study evaluated both the mortality rates and the food consumption referring to the same period (ie, the same year). The appropriate time-lag period was not incorporated into the analysis as data on past exposures were not available. In the event that exposures are changed markedly over time, this may lead to a spurious association between food consumption and mortality. Finally, unmeasured or poorly measured food and beverages consumption as well as lack of measures for important potential confounders can be a major source of bias in our ecological study. Of course, these calculations do not take into account the effects of other dietary intake (eg, salt, spices, additives) that could be of influence on mortality but were not included in the Household Budget Survey. Additionally, consumption of any specific food group may actually just be a marker for a whole range of other socioeconomic, biological and psychological factors (such as poverty, traumatism, stress, comorbidity, etc) that characterised the period of the fall of communism and the civil wars in former Yugoslavia since 1990s, from which no data is available for Serbia during the whole study period. Further, inability to control for bias and confounding factors may be responsible for some inconsistency in our findings in comparison to other studies.

In conclusion, consumption of food and beverages is of potential importance in mortality trends for cancer, ischaemic heart disease and diabetes mellitus in Serbia. Further effort is needed to investigate a possible causative association, using epidemiological analytical studies.

\footnotetext{
Author affiliations

${ }^{1}$ Department of Epidemiology, Faculty of Medical Sciences, University of Kragujevac, Kragujevac, Serbia

${ }^{2}$ Faculty of Medical Sciences, University of Kragujevac, Kragujevac, Serbia
}

${ }^{3}$ Medical College for Professional Studies, University of Belgrade, Belgrade, Serbia

${ }^{4}$ Department of Anatomy, Faculty of Medical Sciences, University of Kragujevac, Kragujevac, Serbia

Acknowledgements The authors thank Zorka Zeba, Dijana Lalovic, Vesna Paunovic and Gabrijela Djordjevski for their technical assistance. Also, authors thank Petar Zivanic for the English language editing of the paper.

Contributors $\mathrm{MI}$ conceived and designed the study, took part in data collection, data analysis, interpretation of the results and manuscript preparation, editing, and review. II, GS and IZ-M performed data analysis, and manuscript editing and review. All authors took part in editing of the final version and gave approval for submission.

Funding This work was supported by the Ministry of Education and Science of the Republic of Serbia, through Contract No. 175042.

Competing interests None declared.

Ethics approval This study is part of a larger research approved by the Ethics Committee of the Faculty of Medical Sciences, University of Kragujevac (Ref. No.: 01-4806), entitled "The survival of patients suffering from the most common chronic diseases (malignant tumours, cardiovascular and cerebrovascular diseases)"

Provenance and peer review Not commissioned; externally peer reviewed.

Data sharing statement No additional data are available.

Open Access This is an Open Access article distributed in accordance with the Creative Commons Attribution Non Commercial (CC BY-NC 4.0) license, which permits others to distribute, remix, adapt, build upon this work noncommercially, and license their derivative works on different terms, provided the original work is properly cited and the use is non-commercial. See: http:// creativecommons.org/licenses/by-nc/4.0/

\section{REFERENCES}

1. European Commission. Europe in figures-Eurostat yearbook for 1999-2010. Health statistics-Atlas on mortality in the European Union. Luxembourg: Office for Official Publications of the European Communities, 2011.

2. Jemal A, Ward E, Hao Y, et al. Trends in the leading causes of death in the United States, 1970-2002. JAMA 2005;294:1255-9.

3. Murphy SL, Xu JQ, Kochanek KD. Deaths: Final Data for 2010. National vital statistics reports; vol 61 no 4. Hyattsville, MD: National Center for Health Statistics, 2013.

4. World Health Organization. The top 10 causes of death Fact sheet No310. Geneva, Switzerland: World Health Organization, 2013.

5. Moran AE, Forouzanfar MH, Roth G, et al. Temporal trends in ischemic heart disease mortality in 21 world regions, 1980 to 2010: the Global Burden of Disease 2010 study. Circulation 2014;129:1483-92.

6. Shaw JE, Sicree RA, Zimmet PZ. Global estimates of the prevalence of diabetes for 2010 and 2030. Diabetes Res Clin Pract 2010;87:4-14.

7. Vandenheede $\mathrm{H}$, Deboosere $\mathrm{P}$, Stirbu I, et al. Migrant mortality from diabetes mellitus across Europe: the importance of socio-economic change. Eur J Epidemiol 2012;27:109-17.

8. Béjar LM, Gili M, Infantes B, et al. Incidence of colorectal cancer and influence of dietary habits in fifteen European countries from 1971 to 2002. Gac Sanit 2012;26:69-73.

9. Naska A, Bountziouka V, Trichopoulou, et al DAFNE Participants. Soft drinks: time trends and correlates in twenty-four European countries. A cross-national study using the DAFNE (Data Food Networking) databank. Public Health Nutr 2010;13:1346-55.

10. Trichopoulou A, Naska A, Costacou T, DAFNE III Group. Disparities in food habits across Europe. Proc Nutr Soc 2002;61:553-8.

11. Keys A, Menotti A, Karvonen MJ, et al. The diet and 15-year death rate in the seven countries study. Am J Epidemiol 1986;124:903-15.

12. Knoops KT, de Groot LC, Kromhout D, et al. Mediterranean diet, lifestyle factors, and 10-year mortality in elderly European men and women: the HALE project. JAMA 2004;292:1433-9.

13. Collado-Mesa F, Barceló A, Arheart KL, et al. An ecological analysis of childhood-onset type 1 diabetes incidence and prevalence in Latin America. Rev Panam Salud Publica 2004;15:388-94. 
14. Gaskill SP, McGuire WL, Osborne CK, et al. Breast cancer mortality and diet in the United States. Cancer Res 1979;39:3628-37.

15. MacDonald J, Brevard PB, Lee RE, et al. Link between diet and cardiovascular disease in Latin America and the Caribbean using geographic information systems. Rev Panam Salud Publica 2009;26:290-8.

16. Zatonski WA, McMichael AJ, Powles JW. Ecological study of reasons for sharp decline in mortality from ischaemic heart disease in Poland since 1991. BMJ 1998;316:1047-51.

17. Government of the Republic of Serbia. The Republic of Serbia: facts about Serbia. Belgrade, 2015. http://www.srbija.gov.rs/pages/intro. php?id=5 (20 September 2015).

18. Ilic M, llic I. Prostate cancer mortality in Serbia, 1991-2010: a joinpoint regression analysis. J Public Health 2015. doi:10.1093/ pubmed/fdv064

19. Marković-Denić L, Vlajinac H, Živković S, et al. Cancer mortality among men in Central Serbia: 1985-2006 survey study. Croat Med J 2008;49:792-8.

20. Vujcic IS, Sipetic SB, Dubljanin ES, et al. Trends in mortality rates from coronary heart disease in Belgrade (Serbia) during the period 1990-2010: a joinpoint regression analysis. BMC Cardiovascular Disorders 2013;13:112

21. Statistical Office of the Republic of Serbia. Demographic Yearbook in the Republic of Serbia, 1991-2010. Belgrade, Serbia: Statistical Office of the Republic of Serbia, 2011

22. World Health Organization Regional Office for Europe. European Health for All Database (HFA-DB). Copenhagen, 2015. http://data. euro.who.int/hfadb/ (20 September 2015).

23. Mathers CD, Fat DM, Inoue M, et al. Counting the dead and what they died from: an assessment of the global status of cause of death data. Bull World Health Organ 2005;83:171-7.

24. Statistical Office of the Republic of Serbia. Bulletins-Household Budget Survey for 1991-2010. Belgrade, 2011.

25. Jensen OM, Parkin DM, MacLennan R, Muir CS, Skeet RG, eds. Cancer registration: principles and methods. IARC scientific publication No. 95. Lyon: IARC Press, 1991.

26. Levi F, Chatenoud L, Bertuccio P, et al. Mortality from cardiovascular and cerebrovascular diseases in Europe and other areas of the world: an update. Eur J Cardiovasc Pre Rehabil 2009;16:333-50.

27. Bosetti C, Bertuccio P, Malvezzi M, et al. Cancer mortality in Europe, 2005-2009, and an overview of trends since 1980. Ann Oncol 2013;24:2657-71.

28. Roglic G, Unwin N. Mortality attributable to diabetes: estimates for the year 2010. Diabetes Res Clin Pract 2010;87:15-19.

29. Tominaga S, Kuroishi T. An ecological study on diet/nutrition and cancer in Japan. Int J Cancer 1997;71(Suppl 10):2-6.

30. Vareiro D, Bach-Faig A, Raidó Quintana B, et al. Availability of Mediterranean and non-Mediterranean foods during the last four decades: comparison of several geographical areas. Public Health Nutr 2009:12:1667-75.

31. Kunitz SJ. The making and breaking of Yugoslavia and its impact on health. Am J Public Health 2004;94:1894-904.

32. Briefel RR, Johnson CL. Secular trends in dietary intake in the United States. Annu Rev Nutr 2004;24:401-31.

33. Chen BK, Seligman B, Farquhar JW, et al. Multi-Country analysis of palm oil consumption and cardiovascular disease mortality for countries at different stages of economic development: 1980-1997. Global Health 2011;7:45.

34. Naska A, Berg MA, Cuadrado C, et al., Data Food Networking (DAFNE) Participants. Food balance sheet and household budget survey dietary data and mortality patterns in Europe. Br J Nutr 2009;102:166-71

35. Béjar Prado LM, Gili M, Ramírez G, et al. Dietary changes and colorectal cancer trends in Spain during 1951-2007. Rev Esp Enferm Dig 2010;102:159-68.

36. Armstrong B, Doll R. Environmental factors and cancer incidence and mortality in different countries, with special reference to dietary practices. Int J Cancer 1975;15:617-31.

37. Grant WB. A multicountry ecological study of cancer incidence rates in 2008 with respect to various risk-modifying factors. Nutrients 2013:6:163-89.

38. Besson H, Paccaud F, Marques-Vidal P. Ecologic correlations of selected food groups with disease incidence and mortality in Switzerland. J Epidemiol 2013;23:466-73.

39. Jarosz M, Sekula W, Rychlik E. Trends in dietary patterns, alcohol intake, tobacco smoking, and colorectal cancer in Polish population in 1960-2008. Biomed Res Int 2013;2013: 183204

40. Lagiou P, Trichopoulou A, Henderickx HK, et al. Household budget survey nutritional data in relation to mortality from coronary heart disease, colorectal cancer and female breast cancer in European countries. DAFNE I and II projects of the European Commission. Data Food Networking. Eur J Clin Nutr 1999;53: 328-32.

41. Lee SA, Shu XO, Yang G, et al. Animal origin foods and colorectal cancer risk: a report from the Shanghai Women's Health Study. Nutr Cancer 2009;61:194-205.

42. Jansen MC, Bueno-de-Mesquita HB, Buzina R, et al. Dietary fiber and plant foods in relation to colorectal cancer mortality: the Seven Countries Study. Int J Cancer 1999;81:174-9.

43. Artaud-Wild SM, Connor SL, Sexton G, et al. Differences in coronary mortality can be explained by differences in cholesterol and saturated fat intakes in 40 countries but not in France and Finland. A paradox. Circulation 1993;88:2771-9.

44. Grønbaek M, Becker U, Johansen D, et al. Type of alcohol consumed and mortality from all causes, coronary heart disease, and cancer. Ann Intern Med 2000;133:411-19.

45. Di Castelnuovo A, Rotondo S, lacoviello L, et al. Meta-analysis of wine and beer consumption in relation to vascular risk. Circulation 2002;105:2836-44.

46. Romeo J, Warnberg J, Diaz LE, et al. Effects of moderate beer consumption on first-line immunity of healthy adults. J Physiol Biochem 2007;63:153-9.

47. Willett WC. Dietary fats and coronary heart disease. J Intern Med 2012;272:13-24.

48. Feskens EJM, Virtanen SM, Räsänen $L$, et al. Dietary factors determining diabetes and impaired glucose tolerance. A 20-year follow-up of the Finnish and Dutch cohorts of the Seven Countries Study. Diabetes Care 1995;18:1104-12.

49. Patterson E, Larsson SC, Wolk A, et al. Association between dairy food consumption and risk of myocardial infarction in women differs by type of dairy food. $J$ Nutr 2013;143:74-9. 